\title{
A Sensorless Switched Reluctance Drive System Based on the Improved Simplified Flux Method
}

\author{
Zhenguo Li *, Andong Song * and Jin-Woo Ahn **
}

\begin{abstract}
This paper describes a new rotor position sensorless control method for SRM drives based on an improved simplified flux linkage method. In the traditional simplified flux linkage method, every phases take turns conduction and current chopping control method is used. Every phases take turns conduction means turning on the incoming working phase while turning off the working phase. This conduction mode causes coupling between turn-on and turn-off angles, which goes against optimal efficiency or torque ripple minimization with sensorless speed control. In the improved simplified flux linkage method, turn-off angle is calculated by flux loop, the turn-on angle can be given arbitrarily and has no relations with the turn-off angle, and the current chopping control method is used. The speed and rotor position can be estimated then. Finally, a sensorless SRM speed control system and an experiment platform with DSP are built and validity of this method is confirmed.
\end{abstract}

Keywords: SRM(switched reluctance motor), Sensorless drive system, Improved simplified flux method, Adjustable turn-on angle

\section{Introduction}

The Switched Reluctance Motor (SRM) is characteristic of doubly-salient structure, with concentrated windings on stator and no windings of any kind or magnets on rotor. Thus, compared with conventional a.c. or d.c. motors, SRM has many advantages, such as simple and rugged construction, low-cost, reliability, wide speed range and robust performance and so on [1]. However, SRM needs the rotor position information for proper operation, which usually is obtained by physical sensors installed in the motor shaft. Therefore, the use of these sensors increases the whole system cost and machine size and sometimes there is no proper position to install sensors in harsh environments. To overcome these disadvantages caused by using position sensor, sensorless techniques attract domestic and overseas researchers' attention all the time.

The rotor position measurement and estimation can be broadly classified into two categories: continuous or specific position acquisition schemes [2]. The continuous

\footnotetext{
* Key Lab of Power Electronics for Energy Conservation and Motor Drive of Hebei Province, Yanshan University, Qinhuangdao 066004, China (1zg@ysu.edu.cn; 916078991@qq.com)

** Department of Mechatronics Engineering, Kyungsung University, Busan 608-736, Korea (jwahn@ks.ac.kr) Received 05 October 2012; Accepted 19 November 2012
}

acquisition scheme exploits the inherent unique characteristic of the three dimensional relationship between the flux linkages or inductance, current and rotor position to obtain the rotor position. This scheme usually is complex in algorithm, including flux linkage method [3], incremental inductance method [4], idle phase excitation method [5], mutual flux linkage method [6] and so on. The specific position acquisition scheme obtains the position information intermittently by current shape or relation between flux and current in the specific position. This scheme can be realized more simply compared with the former, and includes current gradient method [7], flux linkage estimate method based on reference position [8] and simplified flux linkage method [9].

In the traditional simplified flux linkage method, every phases take turns conduction and current chopping control method is used. There needs small memory and simple algorithm. Every phases take turns conduction means turning on the incoming working phase while turning off the working phase, which results in couple between turn-on and turn-off angles, which goes against optimal efficiency or torque ripple minimization with sensorless speed control. So the improved simplified flux linkage method is proposed, in which the turn-on angle can be given arbitrarily and has nothing to do with the turn-off angle.

The current chopping control method is used, and turn- 
off angle is calculated by flux loop. The speed and rotor position can be estimated then. Finally, a sensorless SRM speed control system and an experiment platform with DSP are built, and validity of this method is confirmed.

\section{The Improved Simplified Flux Linkage Method}

\subsection{Determination of the turn-off angle position}

Fig. 1 depicts the measured magnetizing mapping and estimated flux linkage trajectory of a 12/8 SRM. When SRM works in current chopping mode and the turn-off angle is fixed, the flux linkage is a monotone function of reference current apparently, and is defined as reference flux linkage. The estimated flux linkage trajectory in Figure. 1 consist of different reference flux linkages. The phase voltage subtracts the ohmic voltage drop due to the phase resistance, and finally integrated to give an estimated flux linkage. The estimated flux linkage is compared with the stored flux linkage from the estimated flux linkage trajectory. At the time when the estimated flux linkage becomes higher than the stored flux linkage, a trigger signal is generated. I.e. this means that the rotor has just passed the turn-off angle position. The principle is illustrated in Fgure.2, in which subscript character ph is certain phase of SRM and the superscript character $*$ is the reference value.

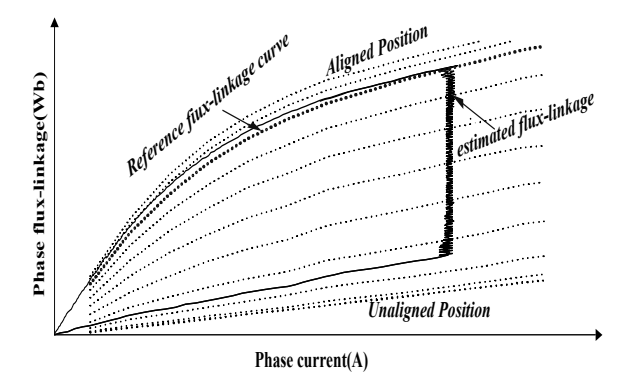

Fig. 1. Magnetizing map and estimated flux linkage trajectory

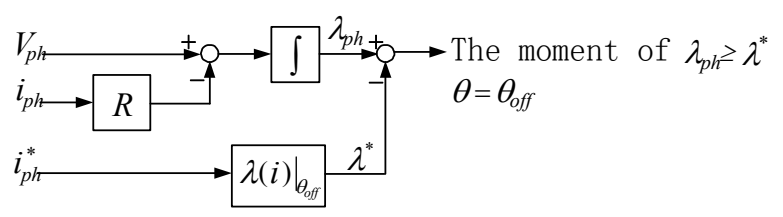

Fig. 2. Block diagram for determining turn-off position

\subsection{Estimation of speed and other position}

In the proposed improved simplified flux linkage method, turn-off angle has been estimated in the part before; the speed and continuous position of rotor are estimated below.

In current chopping method, the distance of two neighboring turn-off angles is shown as (1)

$$
\Delta \theta=\frac{2 \pi}{m \cdot p_{r}}[\mathrm{rad}]
$$

Where $\mathrm{m}$ is the number of phases and $\mathrm{pr}$ is the number rotor poles.

For a designed SRM, $\Delta \theta$ is constant. So the rotor speed of SRM can be calculated by the (2).

$$
\omega_{r m}=\frac{2 \pi}{m \cdot p_{r} \cdot \Delta T}[\mathrm{rad} / \mathrm{s}]
$$

where $\Delta \mathrm{T}$ is the operate time during the $\Delta \theta$.

Due to the measurement error of the voltage and current in the actual system, smoothing is needed in the calculated rotor speed in (2). The continuous rotor position can be estimated in (3).

$$
\theta=\theta_{\text {off }}+\int \omega_{r m} d t \quad[r a d]
$$

Each time rotor rotates to the turn-off position, correct turn-off angle is extracted, so there exist no accumulated error in the estimated rotor position by the equation (3). This position cab is used to determine the arbitrary turn-on angle.

\subsection{Start-up method for the sensorless operation}

The improved simplified flux linkage method don't include start-up section, and other method is used to start the SRM and brings the SRM into synchronous operation. Start-up methods of forced alignment and injecting voltage pulses can be used in this sensorless control system. For the forced alignment method, during start-up, one of the SRM phases is excited, and poles of rotor and stator align in a special position, then the absolute starting position is known. For the injecting voltage pulses method, the three SRM phases are excited at the same time by identical voltage pulses, meanwhile making rotor at a standstill. The three phases peak currents are detected and compared to determinate exciting which phase for SRM start-up.

\section{Sensorless Drive System Based On the Improved Simplified Flux Linkage Method}

Fig. 3 shows the sensorless drive system of SRM based on the improved simplified flux linkage method which is depicted in the above section. This drive system includes a current inner-loop worked in current chopping mode and a speed outer-loop with PI controller. In addition, a flux- 
current curve is off-line measured in advance for a fixed turn-off position. Adjustable turn-on angle is benefit to optimal efficiency or torque ripple minimization.

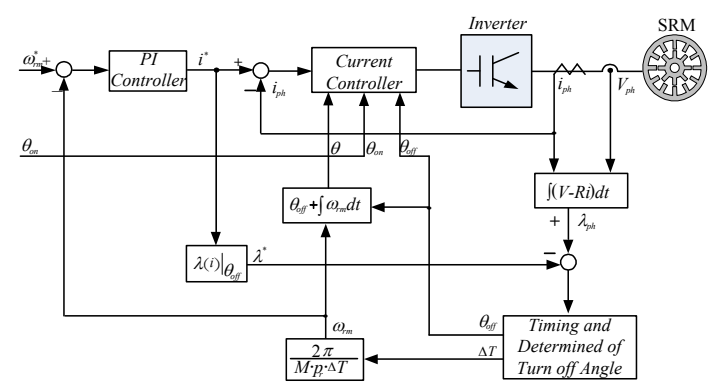

Fig. 3. Proposed sensorless drive system

In the current chopping inner-loop, the switched states in each control period of the inverter are known and the DC bus voltage is constant. So while estimating the phase flux linkage in experiment, the voltage sensor can be eliminated for saving cost. Each time the rotor rotates to the turn-off position, the rotor speed is estimated, and the speed controller gives a new reference current. In other words, the higher rotor speed is, the shorter speed control cycle is.

To take notice that correct compare between the calculated and reference flux linkage is the key to estimate rotor position, so two conditions are needed for the system normal operation. Firstly, the flux-current curve measured off-line for a fixed turn-off position is definitely correct. Secondly, the reference current can not be too small, otherwise the smaller actual current may generate big error between the estimate and the actual flux linkage.

\section{Experimental Results}

\subsection{Parameters of the SRM in experiment}

In order to verify the validity of the proposed method, a $12 / 8$ SRM was chosen for the control object. The rated voltage, speed and power are $300 \mathrm{~V}, 1800 \mathrm{r} / \mathrm{min}$ and $130 \mathrm{~W}$ respectively. The three-dimension map of winding inductance is shown in Fig.4.

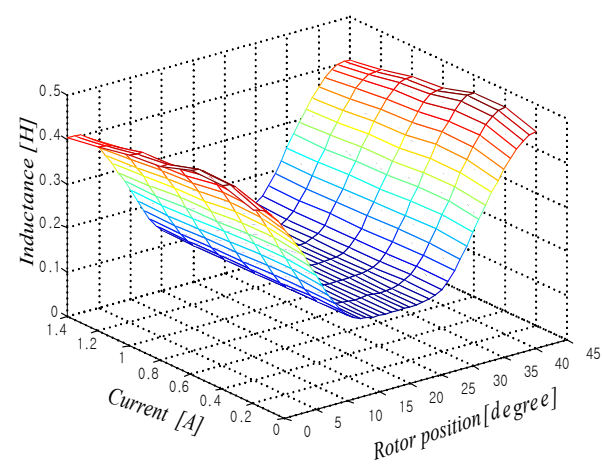

Fig. 4. Inductance profile of a $12 / 8$ SRM

\subsection{Experimental results and analysis}

Fig. 5 shows the sensorless drive experiment platform of SRM. The DSP microarray adopted TMS320F28335 of T.I Corporation, the current sampling and control period is $25 \mu \mathrm{s}$, the DC-link voltage is $300 \mathrm{~V}$, and the load is a dynamometer which can adjust the torque value.

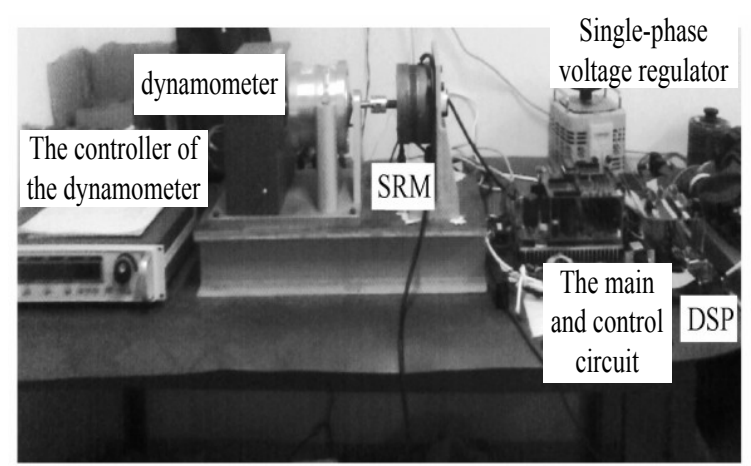

Fig.5. Sensorless drive experimental platform of SRM

Fig.6 shows the experimental principle to verify accuracy of the turn-off angle abstracted from the proposed method. In experiment, a given turn-on angle is compared with the actual rotor position. At the time the actual rotor position reaches the given turn-on angle, a turn-on signal is generated. The turned-off time is determined by comparing the reference and calculated flux linkage. Current chopping mode is used by comparing the reference and actual current in windings. The algorithm above is realized by DSP program.

The turn-off angle for calculating reference flux linkage in flux-current curves is $35^{\circ}$. The aligned position of stator and rotor is defined as $0^{\circ}$.

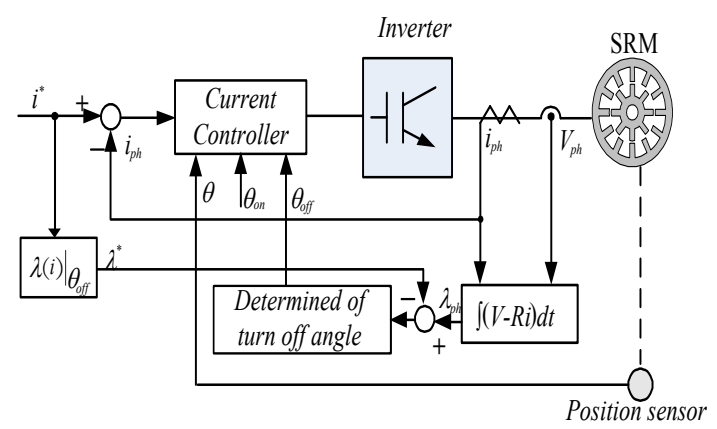

Fig. 6. Control block diagram for determine turn-off position

Fig. 7 shows the experiment results, when the motor runs in steady state at $500 \mathrm{r} / \mathrm{min}$. The turn-on angle is $25^{\circ}$, and the reference current is $1.7 \mathrm{~A}$.

The switch states of each phase include state 1, 0 and -1 , which represents the upper and lower switches are turned on, only one switch is turned on, and the upper and lower switches are turned off respectively. Besides, for the 
phase's flux linkage estimation is useless after the turn-off position, the flux linkage is assigned zero to save the running time.

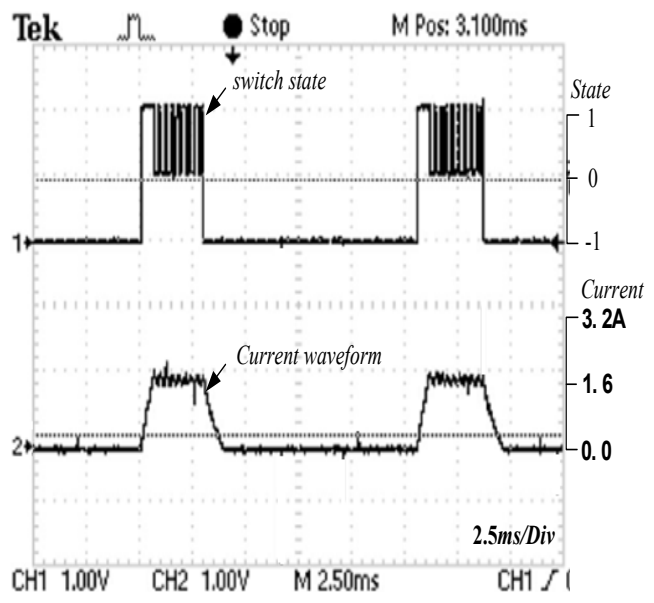

(a) The switch state and current of phase $\mathrm{A}$

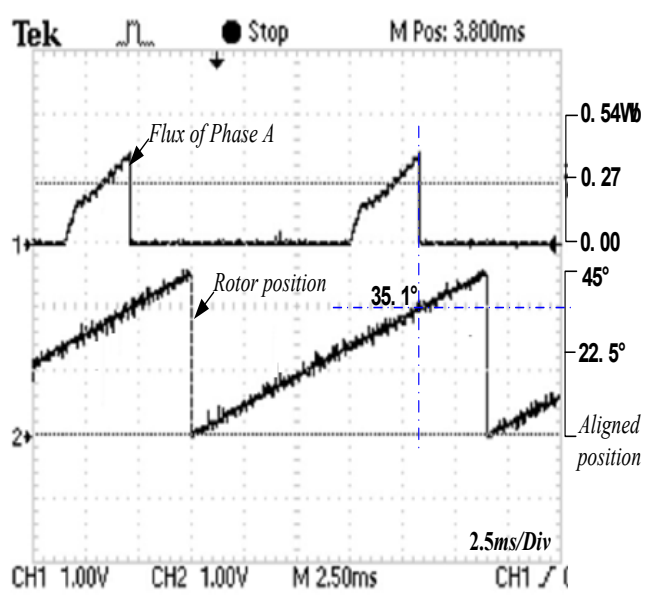

(b) The estimated flux linkage and position of phase A

Fig. 7. Experiment result for determining turn-off position

The experimental result shows that the actual turn-off position is very close to the expected turn-off position. The similar results can be obtained when the system is affected by additive step disturbances of speed, reference current or turn-on position. It proves that the comparing of the estimated flux and reference flux can replace the comparing of the reference turn-off position and the actual rotor position absolutely, and then the speed and other rotor position can be calculated.

The Fig. 8 and the Fig.9 show the experiment results under the rated torque load $(0.7 \mathrm{~N} . \mathrm{m})$ and half rated torque load $(0.35 \mathrm{~N} . \mathrm{m})$ respectively. The corresponding experiment control block diagram is given in Fig. 3 .

PI controller is used in the speed controller and the proportional and integral gains are $0.035 \mathrm{~A} \cdot \mathrm{s} / \mathrm{rad}$ and $0.02 \mathrm{~A} / \mathrm{rad}$ respectively. The rotor speed is estimated every
15 degree, and the speed controller gives a new reference current. To avoid excessive reference current, a current upper limit of $1.76 \mathrm{~A}$ is used.

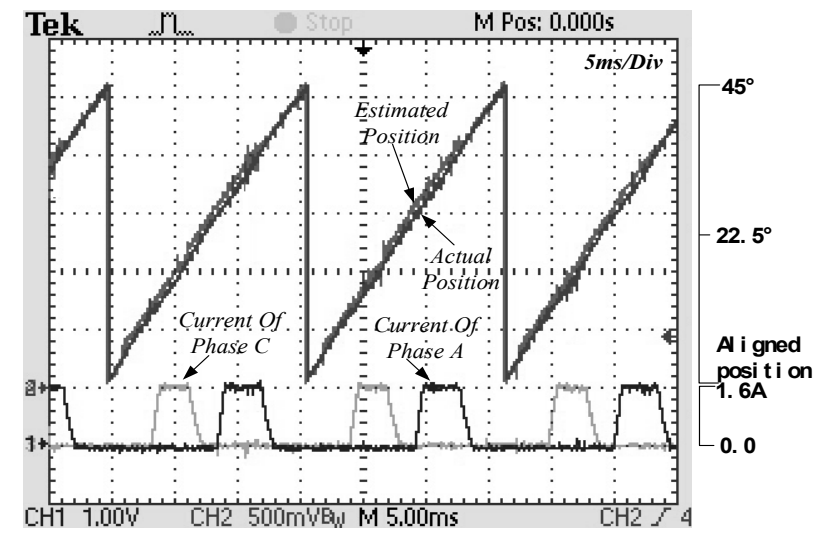

(a) Rotor position and phase current waveform in $500 \mathrm{r} / \mathrm{min}$

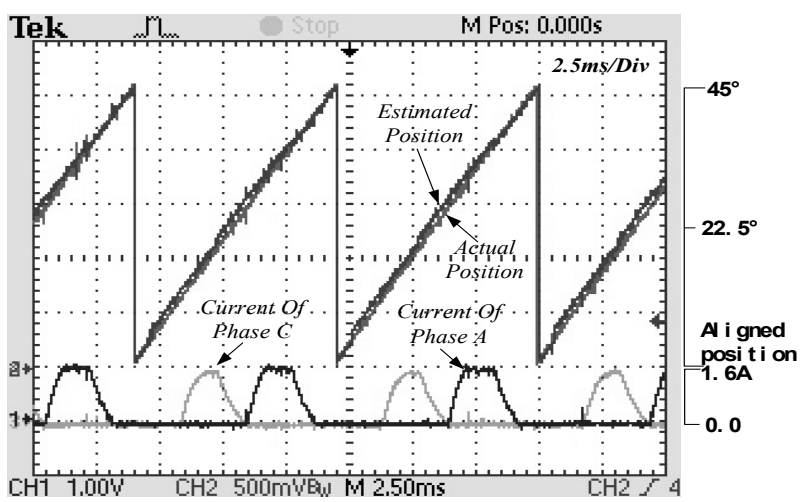

(b) Rotor position and phase current waveform in $1000 \mathrm{r} / \mathrm{min}$

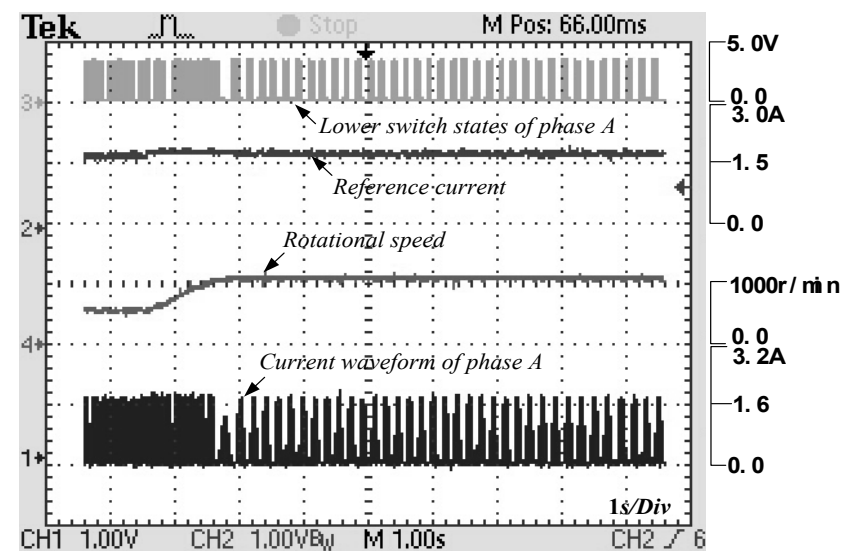

(c) Rotor position and phase current waveform when the reference speed step changed from 500 to $1000 \mathrm{r} / \mathrm{min}$

Fig. 8. Experiment result of sensorless drive system at rated torque load 


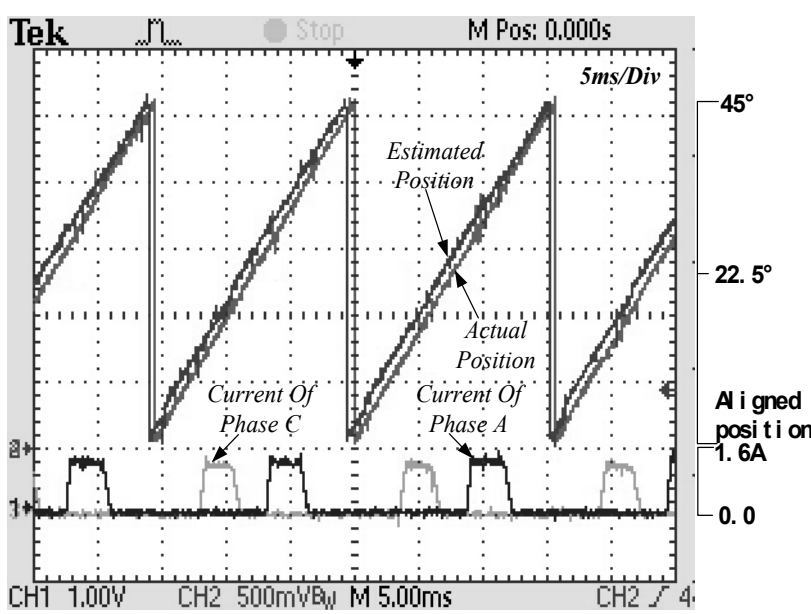

(a) Rotor position and phase current waveform in $500 \mathrm{r} / \mathrm{min}$

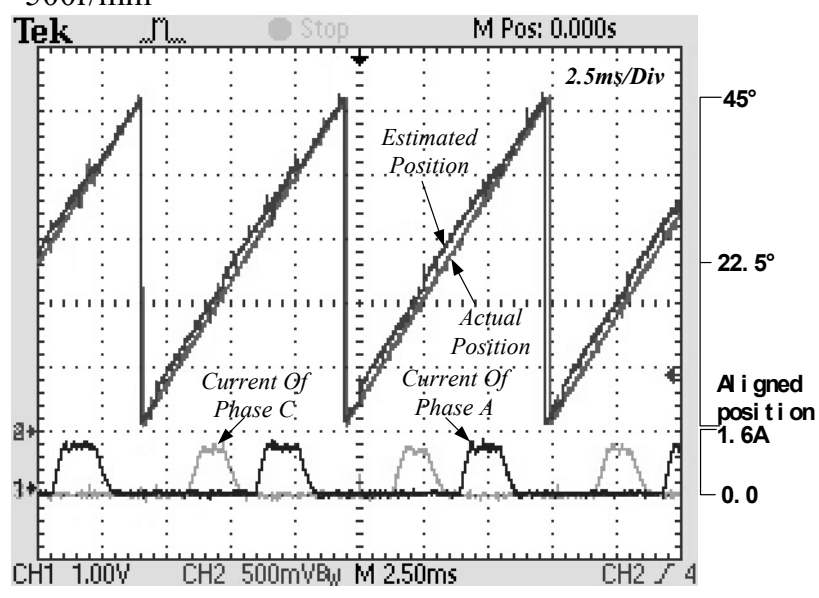

(b) Rotor position and phase current waveform in $1000 \mathrm{r} / \mathrm{min}$

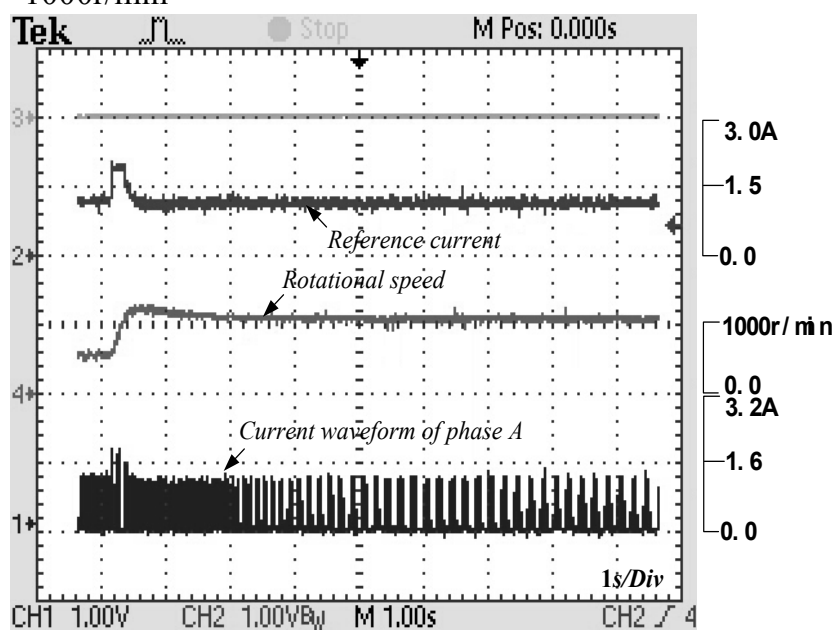

(c) Rotor position and phase current waveform when the reference speed step changed from 500 to $1000 \mathrm{r} / \mathrm{min}$

Fig. 9. Experiment result of sensorless drive system at half rated torque load

As shown in the actual/estimated rotor position and phase current figure, waveforms in each phase are not identical. This is due to little difference in the actual resistance and inductance of each phase. While using the same flux-current curve, the estimated flux of each phase is not identical, which results little difference in the turn-off position of each phase. This problem can be solved by little compensation for each phase.

Seen from the waveform of the speed and reference current response in a step change of reference speed, the speed response exists little overshoot under this PI parameters, and dynamic response is fast with about $2 \mathrm{~s}$ adjustment time. The overall control effect is well.

\section{Conclusion}

In this paper, we propose the improved simplified flux linkage method in which the turn-on angle can be given arbitrarily and has no relations with the turn-off angle, and the SRM sensorless drive system is built. The proposed method works at a fixed turn-off angle and current chopping mode. The position of the turn-off angle can be determined by the proposed method as well as the speed and rotor position. In order to verify the validity of the method, we utilize the proposed method to build the SRM sensorless speed control system based on DSP, and finish lots of experiments, and the result proves the feasibility and validity of the method.

\section{Acknowledgement}

This work is supported by the Natural Sciences Foundation of Hebei Province of China (No. E2010001263)

\section{References}

[1] R.Krishnan., "Switched Reluctance Motor Drives: Modeling, Simulation, Analysis, Design and Application," CRC Press, 2001.

[2] Krishnan R., "Sensorless Operation of SRM Drives : R \& D Status," INCON'01, Vol. 2, pp. 1498-1503, 2001.

[3] J.P.Lyons, S.R. MacMinn and M.A. Preston., "Flux- current Methods for SRM Rotor Position Estimation," Conf. Rec. of IEEE Ind Appl Soc, Vol. 1, pp.482-487, 1991.

[4] S.K.Panda and G.A.J.Amaratunga., "Waveform Detection Technique for Indirect Rotor Position Sensing of Switched Reluctance Motor Drives, Part 1: Analysis,” IEE Proceedings -B, Vol.140, No.1, pp.80-88. Jan.1993.

[5] A. Brosse, G. Henneberger, M. Schniedermeyer, R. D. Lorenz and N.Nagel., "Sensorless Control of a SRM at Low Speeds and Standstill Based on Signal Power Evaluation," Conf. Record of IEEE Industry Appl. Soc., Vol 3. pp.1538$1543,1998$.

[6] I. Husain and M. Ehsani, "Rotor Position Sensing in Switched Reluctance Motor Drives by Measuring Mutually Induced Voltages," IEEE Trans. on Industry Applications., Vol.30, No3., pp.665-672, May/Jun.1994.

[7] Gallegos-Lopez G., Kjaer P C., Miller T J.E., "A New Sensorless Method for Switched Reluctance Motor Drives," 
IEEE Trans. on Industry Applications., Vol.34, No 4, pp.832840, Jul/Aug. 1998.

[8] W.F.Ray and I.H.Al-Bahadly, "A Sensorless Method for Determining Rotor Position for Switched Reluctance Motors," Proc. of IEE Power Electronics and Variable Speed Drives Conference, pp.26-28, 1994.

[9] Qiu Yi-hui, Zhan Qiong-hua, et al., "The Indirect Position Sensing of SRM on the Basis of Simplified Flux Method," Proceedings of the CSEE, Vol. 21, No 10, pp. 59-62, 2001.

[10] Zhenguo Li, baoying hu, Caihong Li, Dong-Hee Lee and JinWoo Ahn, "SRM Sensorless Speed Control Based on the Improved Simplified Flux Method," ICEMS'11, Aug.2011.

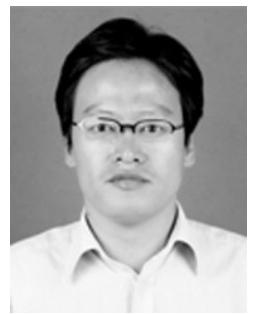

Zhenguo Li received the B.S. degree in electric machinery and electrical apparatus from Shenyang University of Technology, Shenyang, China, in 1994, and the M.S. and Ph.D. degrees in mechatronics engineering from Pukyong National University, Busan, Korea, in 2001 and 2005, respectively.

$\mathrm{He}$ is currently with Yanshan University, Qinhuangdao, China, as an Associate Professor. His major research field is advanced electrical motor control.

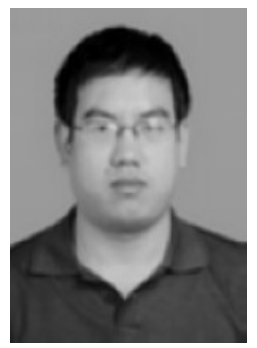

Andong Song received the B.S. degree in Electrical Engineering and Automation from Yanshan University, Qinhuangdao, China, in 2008. His research interest is advanced electrical motor control.

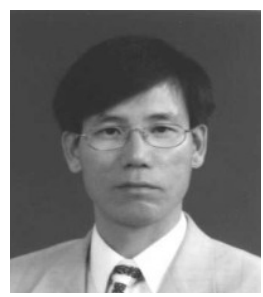

Jin-Woo Ahn received his B.S., M.S., and Ph.D. degrees in Electrical Engineering from Pusan National University, Pusan, Korea, in 1984, 1986, and 1992, respectively.

He has been with Kyungsung University, Busan, Korea, as a professor in the Department of Mechatronics Engineering since 1992. He was a visiting researcher in the Speed Lab at Glasgow University, U.K., a visiting professor in the Dept. of ECE and WEMPEC at the University of WisconsinMadison, USA, and a visiting professor in the Dept. of ECE at Virginia Tech from July 2006-June 2007. He was the director of the Advance Electric Machinery and Power
Electronics Center. He also has been the director of the Smart Mechatronics Advanced Research and Training Center from Aug. 2008 to July 2011 and the Senior Easy Life Regional Innovation System since July 2008, President of Korea Regional Innovation System Association since December 2011 which are authorized by the Ministry of Knowledge Economy, Korea. He is the author of five books including SRM, the author of more than 150 papers and has more than 20 patents. His current research interests are advanced motor drive systems and electric vehicle drives. He has been the Editor-in-Chief of JICEMS.

Dr. Ahn received several awards including the Best Paper Award from the Korean Institute of Electrical Engineers in 2002 and 2011, The Korean Federation of Science and Technology Society in 2003, Korean Institute of Power Electronics in 2007, Park Min-Ho Prize in 2009, Busan Science \& Technology Prize in 2011 and Ministerial Citation of Ministry of Knowledge Economy in 2011, respectively. He is a Fellow of the Korean Institute of Electrical Engineers, a member of the Korean Institute of Power Electronics and a senior member of the IEEE. 